\title{
Teacher's Survival Situation and Countermeasure Research in Rural Schools under the Strong Education
}

\author{
Long Chengxing \\ Mathematics Department \\ Hunan Institute of Humanities, Science and \\ Technology \\ LouDi, HuNan China \\ e-mail: longchengxing@163.com
}

\author{
Luo Zhijun \\ Mathematics Department \\ Hunan Institute of Humanities, Science and Technology \\ LouDi, HuNan China \\ Liang Jinglong \\ Mathematics Department \\ Hunan Institute of Humanities, Science and Technology \\ LouDi, HuNan China
}

\begin{abstract}
Nowadays, rural primary and middle school teachers' problems under the new situation is more and more apparent, Become the new curriculum implementation, strong education pace advancement and rural education reform and development bottleneck. Therefore, transforming of rural teachers' teaching concept, strengthening continuing education system, improving the quality of rural teachers, optimizing rural teacher team, improving rural teachers' social security system to improve rural teachers' working and living conditions to achieve the improvement of rural teachers' survival status, making the rural teachers at rural, happy teaching, latent mental in rural education.
\end{abstract}

Keywords- teachers in rural; survival situation; measures

\section{INTRODUCTION}

Nowadays, the new curriculum standards require teachers a higher demand on mathematics literacy, a new round of the mathematics curriculum reform have made a great change in philosophy, content and implement. Meanwhile, the Hunan Provincial Committee put the strategy of the implementation of education development into effect and decides to become one of the educationally powerful provinces; subsequently, introducing The Plan Construction Education province of Hunan Province. Teachers play the key in achieving the objectives in the mathematics curriculum reform and the strategy of becoming one of the educationally powerful provinces , the treatment of teachers in rural areas, living conditions, social security and the reality demanding reflect severe low happiness index; the situations that the quality of teachers in rural areas is low and the structure is irrational have become the bottleneck of restricting the smooth implementation of the new curriculum, the pace of advancing education strong province, rural education reform and development.

\section{THE SURVIVAL STATUS OF THE PRIMARY AND SECONDARY SCHOOL TEACHERS FROM RURAL AREA}

Currently, the pressure of the primary and secondary school teachers in rural areas mostly come from three aspects: first, the social expectations of them are too high, especially in rural areas, parents have high expectations for their children. In their point of view, studying is the only way to change their poverty status and go to the outside world. Such high expectations make a tremendous pressure on the teachers in rural areas. Secondly, the rural primary and secondary school teachers are facing the excessive pressure on the family life as the rural teachers are suffering the situations in which low income, poor conditions, inadequate social security, neither good economic condition to raise their own children but also maintenance of their own parents. Thirdly, the pressure from the new curriculum, the rarely chance in continuing education, in go out to study and exchange opportunities, plus their own professional qualities bring them a lot of loss when they are facing the new curriculum.

1. The current life situation of rural primary and secondary school teachers

1.1. The treatment of rural primary and secondary school teachers.

In 2005, The OECD state education funding are 5\% share of GDP, and our education budget made a breakthrough of $3 \%$ until in $2008{ }^{[2]}$. The truth that "Two sessions" proposed education budget to reach 4\% of GDP until in 2012 reveals the serious shortage of investment in education, thus, resulting in low wages. According to the survey, $41.3 \%$ of the wages of rural primary and secondary school teachers can not achieve the amount of payment.

Studying and improvement is the objective requirements of the new curriculum for teachers. Good learning environment, a full range of software and hardware facilities and continuing education opportunities are cultural protection for teachers. In our survey, although the central schools have set libraries, but the books and facilities is relatively simple, a considerable part of the school have no any laboratory equipment, not to mention multimedia classrooms and language labs.

In continuing education and training, the administrative department of education rises a lot of ways, but due to the financial constraints, most of the training costs is still paid by teachers individually, which ,undoubtedly, will affect the enthusiasm of teachers to participate in continuing education. What's worse, rural areas have fewer opportunities for 
teacher training, which mere formality, nor targeted training content, it is difficult to achieve updating teacher Education and improving the teaching ability, coupled with the heavy workload of teachers, teacher training can only be arranged at the weekend or holidays, those all become an important factor in affecting teachers continuing education learning.

In housing conditions, we learned from the survey that $46.8 \%$ of the schools provide teachers with less than 10 square meters of housing, only $19.7 \%$ of them provide more than 20 square meters, some primary schools even do not provide housing.

Since ancient times, the teachers regarded as "the most brilliant career under the sun”, but the environment full of nepotism, teachers are contempt by the the inner circle of social character both in the political atmosphere of the" official position ", and in the market economy. In particular, the new curriculum requires equal relationship between teachers and students, which are distort by parents and students in rural areas, and forget to show their least respect for teachers.

1.2. The living conditions of the rural primary and secondary school teachers

The most reliable support for doing any work is stable and happy life, teachers of good or bad quality of life is directly related to whether he threw himself into the cause of education, whether positive thinking can be used to influence students, only when teachers groups have a relatively satisfactory of life, can they have the energy and the mood to involved in the new curriculum, only by understanding the real living conditions of rural teachers, and based on reality, can we ensure the feasibility of new curriculum implementation.

The survey on physical condition, the pressure situation, leisure condition, family situation of the rural teachers in Loudi City reveals that $84.8 \%$ of the teachers' psychological were under sub-health state, about $27 \%$ of teachers suffering from the disease, and presents professional and younger, stomach, cervical spondylosis, sore throat, high blood pressure are common disease the teachers suffered. $42.5 \%$ of teachers were rooted the pressure in work, $29.9 \%$ of teachers were rooted the biggest pressure in the heavy task of teaching, $37.6 \%$ of the teachers were attributed their pressure to the high expectations of society, up to $24.5 \%$ of the teachers can not adapt to the new curriculum requirements.

There are less casual for rural teachers and no specific place for leisure, most of their leisure time spent in schmoozing. When it comes to family circumstances, due to economic conditions and limited housing conditions, most of the teachers were in a difficult situation of "the children can not be conscientious take care of and the old can not be filial ", which led to $89.2 \%$ of the teachers do not want their children engaged in the teaching profession.

1.3. The social security of rural primary and secondary school teachers.

The social security system is designed to ensure the insured persons to meet basic treatment of the disease, to have something they can rely on when they are old and have a house to live in, thus, eliminating their worries and play the role of the social safety net and shock absorber. Although
Medicare is universal, but the rural teachers are in the first line of teaching, they can not be separated from the children, nor get out of the teaching, thus, they have no time to attend to their own health status, when their are getting illness they are first choice is having medicine, and won't go to the hospital until they get a heavy sick. When suffered serious illness or s a specific disease they still need to pay a large amount of medical expenses beside Medicare reimbursement.

2 . The quality status of the primary and secondary school teachers in the rural areas

2.1. The education levels are too low, and the title structure is unreasonable.

Relatively hard living environment due to the backwardness of the rural economy, coupled with poorer terms, it is difficult to attract and retain highly educated graduates, and now most of the first degree of the primary and secondary school teachers in rural areas is a normal school or specialist qualifications. Despite the government eliminating Diploma gap through a variety of channels, less than $60 \%$ of professional rural junior high school teachers' undergraduate education and primary education specialist. Teachers' educational structure has more significant difference when refers to specific schools, some school teachers do not have a graduated from normal universities.

2.2. The serious imbalance in subject structure.

Due to lack of professional teachers, part of rural primary and secondary schools in the survey, exist teach non-learning, school non-teaching phenomena to varying degrees. The phenomenon, such as physical teachers teach foreign languages, language teachers teach physical is not uncommon. Some schools do not even have the conditions for the creation of English, computer and art sports courses. This not only does not meet the requirements of quality education and basic education reform, while also restricting the overall development of students.

2.3. The seriously loss of teachers in rural areas, especially key teachers ${ }^{[1]}$

The loss of secondary school teachers in rural areas come from the initiative loss in which due to the imbalance of economic development in urban and rural areas, the obviously income gap, the better economic school rises a variety of preferential policies to attract key teachers and excellent teachers, causing the township teachers turn to the county, county teachers turn to the provincial capital, underdeveloped areas teachers to the better one's. For rural areas, good teachers trying to run out, miss the high academic quality graduates. Beside, there is passive loss too, the initiative loss result more and more farmers to spend a large capital and efforts to send their children into the city, so urban primary and secondary school students become more and more, the rural school have to select teachers from rural areas. As a result, the rural school teachers wandering by the cycle the low quality.

2.4. The update of education concept is not in place.

New curriculum reformation requires teachers teaching for diathesis. Straighten out the proper relationship between teach-led and study as the main part and establish the educational philosophy of teaching for sustainable human development, completing the transition from traditional 
disseminators of knowledge to the role of facilitator of students' development. As classroom instructors, organizers and collaborators of the students on the subject of the inquiry, teachers should pay attention to the development of each student's personality, to guide students to participate in the teaching process actively, let students gain the emotional experience, knowledge experience as well as meet the needs of the inner self inquiry, what's more the teacher should pay attention to the innovative spirit and practical ability training of their students. But the occlusive information of rural areas, coupled with the loss of young teachers, the aged teacher were failed to update their knowledge into place, they were inadvertent or inability to absorb new knowledge, and traditional teaching methods deep-rooted in their minds, mechanical training and rote memorization played a dominant role.

\section{THE RECOMMENDATIONS FOR SURVIVAL STATUS OF RURAL PRIMARY AND SECONDARY SCHOOL TEACHERS}

3.1. Changing the education concept of teachers in rural primary and secondary school

The concept is the soul of the action, the educational concept of teaching plays the role of guidance and commander in chief of all the difficulties of the teaching reform from the shackles of the old concept of education, do not change the concepts of education, teaching reform is out of the question. Therefore, to establish new concepts of teaching is the primary task of teaching reform. , Rural primary and secondary teaching has not shaken off the shadow of the shadow of examination-oriented education, lack of effectiveness in the examination-oriented education concept not yet been a fundamental change in circumstances, the implementation of the new curriculum reform school. So, through learning and training, to carry out reflection and discussion, raise awareness, strengthen the responsibility of teacher education and teaching the concept of unified requirements up to the quality of education, unified direction up to the new course=

3.2. Improve teachers' continuing education system; improve the quality of primary and secondary school teachers in rural areas.

Improve teachers' continuing education system, an important part of the quality of primary and secondary school teachers in rural areas, so with reality, to establish an effective mechanism for training, so that the quality of the training out, a benefit, rather a form. In order to change the primary and secondary school teachers in rural areas to turn "passive" training into "proactive" training, there are several aspects need to be done. First, to increase the funding of training costs, and try to make teachers less to bear the cost of training, and do not even bear the cost of training. Second, to increase the breadth of the training of teachers, as much as possible so that more teachers to participate in training. Third, increasing teacher training and improve a variety of training systems and training institutions, the development of a wide range of training constraint mechanism to improve the quality of training. Fourth, continuing education to respect teachers 'individual differences and aspirations, consider various incentive system to improve teachers' enthusiasm to participate in the training.

3.3. Deepening the personnel system reform of rural primary and secondary school teachers and establish and improve teachers liquid markets, improve teaching contracts.

Rural teachers can achieve by deepening rural primary and secondary schools and personnel system. First, increase investment in rural teachers, the establishment of rural the teacher characteristics allowance system. The second is to establish a system of regular exchange of teachers for urban and rural areas, the state has adopted policies to support education in rural areas of outstanding teachers must be optimized, rural teachers. The third is to strengthen the management of the preparation of teachers in rural primary and secondary schools to explore the establishment of a fixed preparation of teachers in rural areas with the preparation of the combined flow, reduce the liquidity of the outstanding teachers in rural areas. Fourth, establish and improve teacher's liquid markets, the full implementation of the teachers' employment system, structural wage system, low vocational high school recruits, low employ Vocational ADM remuneration competition mechanism. Fifth, it is a special post teachers consider job back home, to reduce its liquidity. Broaden supplementary channels of teachers in rural schools, the Government has adopted various effective measures to guide and encourage outstanding graduates to rural teaching.

3.4. Improving the working conditions and the social security system of rural primary and secondary school teachers, considering what teachers are worries about.

The obvious difference in urban and rural teachers in rural schools in order to retain teachers, especially outstanding teachers, to try to improve their working and living conditions, its unique value and significance so that they can find work. The one hand, we should actively improve the working and living conditions of the rural teachers, rural teachers living urbanization, so that they can feel at ease during their work; establish and perfect the social security system of rural teachers on the other hand, the pension insurance, housing provident fund, medical insurance gold and other social security programs in accordance with uniform standards, the provincial coordination, and really let the majority of rural primary and secondary school teachers enjoy the same treatment and urban teachers, rural teachers worry about.

3.5. Concerning the protection of the rights and interests of rural primary and secondary school teachers, to proceed with the rights and poverty and spiritual poverty of them.

Improving the wages of rural primary and secondary school teachers, the implementation of the social security benefits is to solve the material interests of rural primary and secondary school teachers, "empowerment" and "energizer" address the importance of the right to primary and secondary school teachers in rural areas of poverty and spiritual poverty way. This "empowerment", is given to teachers to teach in accordance with the law, according to activists, to supervise the administrative departments of education, school administration leadership powers running right. "Energizing" teachers through job training and continuing education to 
improve and expand their personal development and living space, so they want to work and help, there are ways to do want to do in practice to see their hopes and future, to accomplish something, to make a difference. Therefore, it is necessary to improve the education system and the educational environment, and earnestly solve the primary and secondary school teachers in rural areas "helpless", "rogue", "hopeless" and "inaction" in the "rights" and "spirit" completely "out of poverty".

\section{REFERENCES}

[1] Wang zede, Zhao shangjing. Problems and Countermeasures of China's Rural Teachers' Team Building [J], education exploration, 2011 (8):102-104.

[2] Ma guoxian, Ma zhiyuan.The proportion of education expenditure to GDP: International Comparison and strategy recommendations $[\mathrm{N}]$, educational development study, 2009.3.

About the author: Long Chengxing(1979-), male (Han), Lianyuan city Hunan province, Lecturer, Master, is principally engaged in the application of statistical research.

Fund: Education reform project in Hunan Province "The research and practice on curriculum reform of Mathematics and Applied Mathematics <Major direction of mathematics education> under the background of new curriculum of Senior Middle School "; reformation subject of Hunan Institute of Humanities Science and Technology (RKJGY1101)

Author Tel: 13762800987 (Mobile phone); 0738-8325105 (Office)

Author E-mail: longchengxing@163.com

Address: Hunan Loudi, Hunan Institute of Humanities Science and Technology, Mathematics and Applied Mathematics Department (417000) 